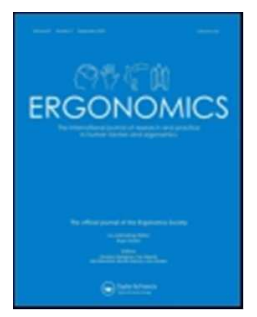

\title{
A framework to support human factors of automation in railway intelligent infrastructure
}

\begin{tabular}{|r|l|}
\hline Journal: & Ergonomics \\
\hline Manuscript ID: & TERG-2012-0300.R3 \\
\hline Danuscript Type: & SI - Beyond Human-Centered Automation \\
\hline Complete List of Authors: & $\begin{array}{l}\text { Dadashi, Nastaran; University of Nottingham, Human Factors Research } \\
\text { Group } \\
\text { Wilson, John; Network Rail , ; University of Nottingham, Human Factors } \\
\text { Research Group } \\
\text { Golightly, David; University of Nottingham, Human Factors Research Group } \\
\text { Sharples, Sarah; University of Nottingham, Human Factors Research Group }\end{array}$ \\
\hline Keywords: & $\begin{array}{l}\text { transport ergonomics < Application Domains, decision making < } \\
\text { Psychological Aspects, human factors integration < System Performance, } \\
\text { complex systems < System Performance }\end{array}$ \\
\hline &
\end{tabular}




\title{
A framework to support human factors of automation in
}

\author{
railway II
}

\author{
Nastaran Dadashi* John R Wilson $* \& * *$ \\ David Golightly* and Sarah Sharples* \\ *Human Factors Research Group, University Park, University of Nottingham, NG7 2RD \\ UK (Tel: 115-9514040; e-mail: nastaran.dadashi@ Nottingham.ac.uk). \\ **Network Rail, No 40 Melton Street, London, NW1 2EE
}

\begin{abstract}
Technological and organisational advances have increased the potential for remote access and proactive monitoring of the infrastructure in various domains and sectors water and sewage, oil and gas, and transport. Intelligent Infrastructure (II) is an architecture that potentially enables the generation of timely and relevant information about the state of any type of infrastructure asset, providing a basis for reliable decision making. This paper reports an exploratory study to understand the concepts and human factors associated with II in the railway, largely drawing from structured interviews with key industry decision makers and attachment to pilot projects. Outputs from the study include a data processing framework defining the key human factors at different levels of the data structure within a railway II system and a system level representation. The framework and other study findings will form a basis for human factors contributions to systems design elements such as information interfaces and role specifications.
\end{abstract}

\section{Practitioner summary}

The framework reported in this paper can become the basis for human factors guidance of engineers, developers and business analysts in developing appropriate levels of information display, automation and decision aid into rail II. Guidance will be aimed at the different functions and activities within multi-layered, multi-agent control.

Keywords: rail systems, II, complex systems, automation, human factors guidance

\section{Introduction}

Automating various functions to improve and enhance railway operations has become increasingly prevalent. This is due to growing demands on railway capacity (e.g. Dft, 2011) and parallel pressures on costs of operation (McNulty, 2011). Opportunities to meet demands are potentially offered by technological advances. One such advance is 
railway Intelligent Infrastructure (II), currently a key concern of many rail infrastructure owners, and with a major project launched in Great Britain in 2006 by Network Rail. The aim of the project was to integrate data collected from different types of remote condition monitoring equipment in order to better understand the condition and behaviour of railway assets such as track, point machines, signals etc. Goals of the project are to model deterioration of particular assets, predicting their optimum life to avoid failures; planning rectifying action if the asset fails, including notification of relevant human actors in the wider distributed socio-technical system; and move from reactive "find and fix" to proactive "predict and prevent". Intended performance outcomes and fewer infrastructure failures, fewer consequent delays to the service and more effective deployment of human resources (e.g. fewer inspection visits).

Despite their obvious appeal, automation control processes in the railway have not always had the expected or hoped-for outcomes - one example being the lack of consistency in understanding how Automatic Route Setting (ARS) works to support railway signalling (Balfe et al., 2011). As always, the risk is that system developers fall into the trap of automating the straightforward and easy tasks, leaving human operators with a mixed selection of those that are cognitively demanding (Bainbridge, 1983; Hollnagel and Woods, 2005). Even with technology that is apparently well designed in terms of Human Machine Interaction (HMI), processes involving automation need to be sensitive towards the complex socio-technical nature of rail operations, with its legacy infrastructure, multiple stakeholders and deeply embedded working practices (Wilson and Norris, 2006).

This paper reports a first exploratory study of railway II investigating knowledge and information requirements for complex, multi-agent, multi-layered distributed control systems with automation at their core. A data processing framework has been developed to represent different levels of data, information, knowledge and intelligence within II, coupled with an identification of relevant human factors considerations within layers of this framework, in order to support development and implementation of a successful railway II.

The contributions of this paper are:

- A description of II, an emerging form of socio-technical system embracing Remote Condition Monitoring (RCM) and automation, as a distributed supervisory control environment;

- Identification of key human factors associated with II derived from experts and observational data; 
- A framework based on an ISO 13374 approach to formalising II that illustrates both the levels of information processing and where specific human factors lie; and

- A schematic illustrating the wider system of II and where the interactions with people can lie.

Some of the technical literature on II raises human and organisational issues implicitly. However, at the time of carrying out this study and of writing this paper, there had been no explicitly ergonomics/human factors published contributions to understanding and development of railway II, and few if any for other infrastructure industry sectors. However, there are related areas of published human factors on which the nascent field of Intelligent Infrastructure human factors can draw as summarised in the following section.

\section{Background}

\subsection{Intelligent Infrastructure}

Reliable sensors, sophisticated algorithms and advanced surveillance systems have enabled live monitoring of the infrastructure in complex work environments. This architecture has different names in various industries, such as Condition Monitoring Systems in power plants (Hameed et al., 2009), Condition Based Maintenance in mechanical systems (Jardine et al., 2006), Structural Health Monitoring in aviation (Buderath \& Neumair, 2007) and Pervasive Healthcare in medical systems (Drew \& Westenskow, 2006). For railways, this type of interconnected sensing and decision making technology has been referred to as Intelligent Infrastructure (Network Rail et al., 2007). The idea of II systems in Network Rail (NR) was initiated in 2006, due to the need for change in the maintenance regime. NR owns and maintains the GB railway infrastructure and provides operational service to train operating companies.

In 2007, a good practice guide was produced by NR, Metronet, Tube Lines and the Railway Industry Association (Network Rail et al., 2007) to facilitate an understanding of the concept of II. The objective of II as presented in the good practice guide is 'to deliver improvement by application of intelligence through the infrastructure design and maintenance cycle' (Network Rail et al., 2007, p.3). Collecting and analysing integrated information about the condition of railway assets was expected to improve maintenance efficiencies, enhance safety and operational performance, and lead to a more affordable railway.

Network Rail's high level model of remote condition monitoring is shown in Figure 1 (subsequently modified in 2010). This is a very simple high level work flow; it shows the 
data sources, transformation links, a strategic II solution (i.e., the magic box!), and end user interfaces. Little was known at the start of the II project about the knowledge and information requirements that were going to enable the box in the middle of the diagram to be a 'strategic II solution'.

[Figure 1]

Previous research studies have mainly focused on developing more sophisticated and advanced RCM systems for the railway (Marquez \& Schmid, 2007; Hull, Roberts, \& Hillmansen, 2010). Despite detailed and on-going work, conducted to understand and improve RCM systems in the railway (Lagnebäck, 2007; McHutchon, Staszewski, \& Schmid, 2005), almost all of the limitations apart from the technical issues still persist.

Aktan et al., (1998) conducted exploratory research to investigate the issues associated with remote sensing of the asset conditions during live operations while developing highway bridges. They suggested three main factors to be considered in order to develop an effective II system:

- The knowledge required for diagnosing problems;

- The technology necessary for transmitting the knowledge; and

- The people who will work with the technology.

Of these three factors, technology is already highly advanced, especially with the advent of highly sophisticated algorithms, artificial intelligence applications, neural network algorithms, etc. (Adeli \& Jiang, 2009). On the other hand, the history of technological disappointments over the years tells us that the other two factors (i.e. knowledge and people) will be more difficult to tackle. Although system developers often wrongly assume that they can overcome this lack of understanding through additional technical functionality, in practice this may lead to more problems (Hollangel and Woods, 2005).

The challenge of implementing automation in the form of II for the railways is particularly acute, because of the multiple dimensions over which the system can be considered 'distributed' and the complexities that result in terms of both building a reliable architecture, and a human-interpretable output.

First, the assets themselves are distributed. There may be millions of assets in a technical system as broad as a national railway infrastructure, with many sensors required to present an accurate picture of an asset as complex as a bridge or level crossing. Synthesising and presenting such complex data to support effective action requires a detailed understanding of the context in which asset management work takes place. 
Second, the analysis of the data (the 'intelligence') may be distributed between analysis localised in the sensors themselves, further analysis at some central point, and analysis conducted by an operator in order to diagnose and act upon an alarm. Therefore, a clear understanding is needed of the process of transfer between pure data into knowledge for action, and where the functions that support that transfer should lie.

Finally, in the socio-technical system that is the railway, people are themselves distributed both physically and across roles, and their decisions are distributed over time. A local maintenance engineer may need only critical diagnostic information in order to effect emergency repairs on an asset that is about to fail; a strategic planner in a central office may be using analysis based on weeks, months or years of data to prioritise renewal regimes. Understanding these roles is critical to effective HMI, and understanding the interdependency between the roles is crucial to make sure the system is effective. Woods and Branlat (2010) argue that control in such environments is deeply rooted in what various agents know about the function of other actors involved in the system - their goals and, critically, the constraints within which they are working. One way this would manifest itself in maintenance is ensuring that technical planning and financial planning both work from an integrated system that affords visibility of each other's' constraints (Kans and Ingwald, 2008). The distribution of action in time is also suggestive of layers of action occurring at a different pace depending on the requirements of any cycle of awareness, decision-making and response (e.g. a faster, reactive response by a maintenance operator to an imminent failure, as opposed to the longer proactive strategic response of a maintenance planner). This has potential parallels with the ECOM (Extended Control Model) model (Hollnagel, 2007).

ISO 13374 sets out an approach to develop and deliver advanced condition monitoring and diagnostics, built around a six stage process architecture (see Figure 2) comprising

1- Data acquisition

2- Data manipulation

3- State detection

4- Health assessment

5- Prognosis assessment

6- Advice generation.

While advice generation presents the highest level of synthesis and analysis of data presented to the operator, the architecture emphasises it should be possible to access data at any stage of this process. Reflecting this, the standard also gives initial guidance for the HMI of such systems, for example by recommending that different areas of the 
screen are used to present different levels of analysis from each of the stages above so that the operator can see advice, but also the preceding layers of analysis that have lead to that advice (ISO 13374 Part 1). Also, the standard emphasises on the importance of different roles, and therefore different views on the same data set. The standard does not elaborate further, however, as the specifics of implementation would need to be modified to the specifics of any deployment domain, functions and roles.

[Figure 2]

\subsection{Study questions}

Network Rail, the GB rail infrastructure provider, had embarked on a major programme of developing an Intelligent Infrastructure system. This effort has been based on ISO13374, and therefore there was a need to develop not just HMI design guidance, but also guidance on the wider human factors and more general human-centred deployment of II technology. This posed three research questions that drove the study presented in this paper:

1- What is railway II?

Early familiarisation work by the lead researcher (ND) involved attachment to relevant technical projects, attendance at workshops, and informal discussions with key company opinion formers and decision makers. It soon became apparent that, at that time, there was no consistent understanding of II within the GB railway community. It was therefore necessary to identify the scope and goals of an II system in order to determine the functions and roles that would be influenced by its introduction.

2- What are the human factors associated with railway II?

Despite greater levels of automated data collection and analysis, people are still at the core of II systems. Good design and implementation requires explicit definition of the key human factors and the systems requirements they generate. Therefore, a second question was to ascertain from subject matter experts, either through explicit reference or through the implication of their understanding of II, what they perceived to be the major issues for the people using II within rail.

3 - What is the data processing associated with railway II systems?

In order to guide the knowledge and information required for better implementation, it was important to understand the flow of information and stages of work for hypothetical (no working system was then in place) II tasks. One of the inevitable features of a 
railway II is a greater automatic monitoring and ideally management of the states of key railway assets. Therefore, knowledge of which operators (from geographically dispersed control rooms and other sites, including on track) will be responsible for different functions, their goals and the sequence of their tasks are required in order to enable appropriate adaptive automation fitting with existing human roles and responsibilities.

A key deliverable of this work was a data processing framework that is more suited to managing a human factors contribution than is the ISO 13774 framework. This should be detailed enough to generate specific design and implementation guidance for immediate potential issues, as well as being applicable later for future design decisions on, for instance, robotic control of maintenance and repair processes.

\section{Methods}

This paper draws its information mainly from semi-structured interviews, themselves part of familiarisation phase whilst the lead researcher (ND) was working as a participant observer in Network Rail as part of their Ergonomics Team. The early stage of the research, coming at the beginning of a three-year study of $\mathrm{HF}$ within rail intelligent infrastructure, demanded an exploratory and qualitative approach to data collection.

In a review conducted by Roth (2008) to identify the requirements of adopting Cognitive Work Analysis, it was noted that despite the extensive application of these methodologies in identifying and exploring highly cognitive work settings; it explores two features: 1- examination of domain and its constraints and 2-identification of the practitioners knowledge and strategies. Since in this study, there was no existing system on which to observe or model actual operator behaviour or evaluate existing HMIs, using hierarchical, cognitive task and cognitive work analysis were not appropriate. The findings from this study revealed some of these unknown features and subsequent work was conducted with existing conventional remote condition monitoring systems and maintenance operations. A description of some of this work using cognitive work analysis and critical decision method can be found in Dadashi et al., (2013).

\subsection{Participants}

Twenty semi-structured interviews were conducted between November 2009 and January 2010 with rail staff who were knowledgeable about, or were potential managers and users of, II and its information systems; the interviewees were drawn from several functions and levels of seniority. The first interviewees were chosen on the basis of the suggestions of experts who attended an II workshop as well as on the recommendation of Network Rail's Director of Engineering at the time; snowball sampling was used 
afterwards. Participants were drawn from the companies and organisations that were involved with the II project - supply chains, developers and major infrastructure enhancement projects.

\subsection{Design}

Information sheets were sent to participants prior to the study to introduce it and to provide a set of questions to be asked during the study. These questions were formed during the familiarisation process and were confirmed by Network Rail's Engineering Director at the time. They are listed below:

1. What do you understand to be the future of II for Network Rail?

2. What do you think is the purpose of II?

3. Do you consider RCM as a type of II?

4. What does 'remote' in RCM mean?

5. What does 'intelligent' in II mean?

6. How will the information required for an II be captured?

7. What do you think are the main functions of an II information display?

8. Which control rooms need to be in direct contact with II systems?

9. What are the challenges for designing an effective II system?

10. What are the main roles and responsibilities of operators working with II systems?

Interviewees were also asked to comment on, validate informally and if appropriate add to a first II data processing and human factors framework. Participants were not limited to responses to the questions presented to them. Depending on their expertise and domain of work, some questions were elaborated, whereas some remained unexplored. For example, a member of the Information Management team would not know much about question '10', which refers to potential roles and responsibilities of future railway II systems. An Olympus ${ }^{\mathrm{TM}}$ digital voice recorder was used, with permission of all participants, to record the interviews. An information sheet was designed to guide the participants throughout the interviews.

\subsection{Analysis}

Twenty hours of interviews were transcribed (approximately 55,000 words) and analysed. Thematic content analysis (Miles \& Huberman, 1994; Neale \& Nichols, 2001) followed by an inter-rater reliability analysis of selected interviews were used for this purpose, and Nvivo ${ }^{\mathrm{TM}}$ software used for the data analysis. 
The transcribed interviews were presented on a Microsoft Excel ${ }^{\mathrm{TM}}$ spreadsheet. Columns of this spreadsheet represented participants' comments focusing on similar concepts (technology, definition, challenges, etc.). Rows of the spreadsheet show the number of participants commenting on those similar concepts; an example extract from the spreadsheet is shown in Figure 3.

[Figure 3]

Transcripts were coded three times with three different aims. The first round of coding interview transcripts started with a set of classifications but evolved as new concepts emerged. This was focused on developing a general understanding of railway II. Issues associated with definitions, benefits, roles and functionalities of railway II were explored.

The second round of coding addressed human factors issues. It was clear from the general description of II that although intelligent infrastructure itself is a relatively new area for human factors research and guidance there were a number of human factors contributions which would help our understanding. These contributions could inform guidance on information display interface design, appropriate automation, and interaction with robotic tools and repair systems, role allocation and development and configuration of the type of distributed and collaborative system typified by intelligent infrastructures. Examples include development of insight and guidance for collaborative engineering (Patel et al., 2012), socio-technical systems (Carayon et al., 2006), adaptive and human centred automation (Kaber and Endsley, 2004). In addition one of the questions asked about potential challenges for the project, mainly to encourage participants to talk about different problems with development and implementation. These challenges and problems were then interpreted in the light of potential human factors such as mental models, decision making, monitoring, organisational culture, planning, human reliability, situation awareness, user engagement and workload.

Finally, it was important to capture participants' views about the data processing of the future railway II. The transcripts were therefore re-reviewed for the third round, this time with a focus on the work and information flow of current RCM systems in use and those for potential II systems of the future. The headings used to organise this review were as follows: asset, sensor, data, data processing, database, information, information development, knowledge, knowledge integration, and intelligence.

Nvivo ${ }^{\mathrm{TM}}$ was used to organise these codes and facilitate the merging of different groups of codes. All of the headings used in the three rounds of coding were commented on by two members of the Ergonomics Team. Furthermore, to facilitate the assessment of 
consistency of the coding, one of the members of the Ergonomics Team coded two of the selected interviews in terms of the Human Factors issues. An inter-rater reliability analysis using the Kappa statistics was performed to assess the consistency (Landis and Koch, 1977).

\section{Findings}

\subsection{Railway intelligent infrastructure}

Although individual interviewees did not have a consistent definition of the concept, the data collected from the sample did help with an understanding of the potential functionalities, roles, benefits, and human factors involved in railway II. Intelligent infrastructure in NR has been defined, pragmatically, as a means of support to more reliable and effective railway maintenance. However, the extent of its capabilities varies in the eyes of different potential users. Maintenance staff (maintenance control centre, railway engineering) viewed the systems as somewhat more advanced remote condition monitoring (RCM) systems, members of the infrastructure investment and corporate development teams viewed it as pioneering technology that could "solve all" railway problems and others were more cautious:

"II introduced so that Network Rail can achieve significant budget shortfalls due to recent economic changes. We need to diagnose from the data that we have and inform the relevant people, otherwise, that data is pointless."

II provides information about assets to support real time condition monitoring as well as high level asset management, with potential benefits targeted at safety and efficiency, more informed scheduling for the maintenance regime, and reductions in the costs associated with poor maintenance including less frequent regulator fines due to delays. The intelligence can either be built into the asset or can lie in the interpretation of the information captured from that asset, thus supporting diagnosis, prediction or initiation of repair or replacement.

Distribution of the II can be layered and distributed both centrally and locally, meaning that there are a multiplicity of human and computer roles and responsibilities with different demands and priorities. Three main human roles for the first wave of implementations were identified in the interviews as control room operators, track workers and strategic analysts.

Control room operators are responsible for responding instantly to high priority alarms. They are based in local or regional control rooms, supporting an 
operational railway by interpreting alerts and other information, making diagnoses and conducting temporary corrective actions if possible. Track workers receive information from control room operators regarding a potential failure and then feedback information about the condition of that asset obtained from on-site visits. Staff in control rooms (or possibly on track) will be informed of a defect through an alarm or an alert; their knowledge of the environment (showing the importance of "local knowledge") and of the level of risk associated with that fault will support choice of corrective actions. Strategic analysts receive diagnostic reports from control room operators in order to make decisions about future plans, speed restrictions, maintenance regimes, etc. and feed that information back to both control room operators and track workers. This higher level of analysis is conducted in central control locations, where responsibilities lie for informing future policy and strategy towards adjustments, metrics, trends and other parameters to support permanent corrective actions. It is highly likely that with increased use of advanced II these roles will merge, with track staff being responsible for more responses to alarms or control room operators triggering on-site robotic repair devices. The main functions of all staff interacting with railway II systems will be monitoring, problem solving, alarm handling, fault finding, diagnosis, planning and optimization, and human-machine interfaces must support all these.

Interviewees' knowledge of existing RCM systems and their assumptions about the proposed II system led to the identification of a number of challenges. Technical challenges were mainly noted by the members of the Information Management team (responsible for designing and managing the development of the pilot), including the need to collect and monitor dynamic asset data (e.g. trains) and static, to have more accurate Geographical Positioning Systems (GPS) and algorithms for predictive intelligence. These challenges were reported as manageable but challenges for business change or corporate development could have a fundamental impact. These start to raise human factors problems such as user engagement, users with different priorities (e.g. conflict between running trains and carrying out engineering work), enabling diagnosis to optimise performance without risking safety, and undertaking safety critical assurance.

\subsection{Human factors}

The second round of coding analysed the interview transcriptions in terms of the human factors associated with the potential II systems. Some of the issues reported below (and see figure 4) are grounded in the earlier familiarisation exercise and others emerged from the semi-structured interview study. 
Kappa statistics was used to determine the confidence of the coding with regards to the human factors issues. The mean inter-rater reliability for the two raters for the 11 human factors issues was found to be Kappa $=0.53(p<0.001), 95 \%$ CI $(0.504,0.848)$ and each of the individual Kappa values was within the confidence range $(0.504,0848)$.

The factor categories are not mutually exclusive and to illustrate this a number of issues are represented in the following scenario with relevant human factors in parentheses.

Scenario: A circuit breaker is located in a very busy junction (local knowledge); it has two other circuit breakers adjacent to it (situation awareness). Sensors attached to the circuit breaker record information about its condition every 30 seconds (system reliability) and send them to a database (system reliability). The data stored will be analysed through the pre-defined algorithms to enable state detection (automation). If it has a significantly different condition from the circuit breakers' normal condition it will generate an alarm (automation) to inform the operator about the abnormality (monitoring). The operator receives the alarm and analyses it to find the potential causes of the detected abnormality (decision making). He/she uses the information presented on the SCADA (Supervisory Control and Data Acquisition) systems (human machine interaction, monitoring, automation, system reliability), consults with his/her colleagues (organisational culture, collaboration) to diagnose the fault (decision making) and to identify the potential corrective action required. Following this understanding, the operator has to plan (planning) the optimum corrective action (safety and human reliability) and to do so he/she has to consider external factors (situation awareness), such as time of failure (e.g. peak time) and the feasibility of track access to conduct onsite maintenance work, etc.

This scenario shows that in most cases several human factors codes were in analysis, emphasising the interdependencies and complexities in IIs. Also some of the factors (e.g. systems reliability) are tangentially associated with human factors, especially when the system is viewed as the human-machine or socio-technical and not purely the technical system. Although they mostly had a technical orientation, participants highlighted the need to understand the role of the human operator, and its effect on workload, task design, situation awareness, decision making, monitoring, human computer interaction, planning, system reliability and organisational culture.

Participants noted that the biggest challenge facing II lies in the business change. Introducing new technology that aims to centralise and integrate existing technologies will effect the way people perceive and perform their roles. This is particularly because new methods of diagnosis and prognosis will be adopted 
meaning that experienced operators will have to depart from their traditional ways of working. II is viewed as a decision aid, participants (mostly at the managerial level) viewed II beneficial since it can analyse many parameters simultaneously and would lead to "better" decisions. However, technicians and operators stated concern regarding not being in the loop.

"There are huge amounts of expertise involved with the decision making and fault finding, a lot of people (designers and developers) are being surprised by knowing what exactly happens to an asset. To be honest we really want to know how an expert does his/her job"

Introducing prognostics functionality and being able to predict an asset's life, requires detailed situational understanding. Therefore situation awareness should be supported by the II sociotechnical system and the interface, from a process point of view, different operators, with various roles and responsibilities and priorities would utilise II, therefore understanding the context of their work setting and their requirement during various stages of their activities is essential.

II has been identified by participants as ideally a self-monitoring and self-diagnosis interface, but experience shows that people have to react to some extent as supervisory controllers. They will have to monitor a combination of remote condition monitoring data, network performance and train data, prediction and decisions emerging from II and, for some, the traditional information from visual inspection.

Handling faults within railway requires planning along various control centres and operators. For example, the maintenance team should be informed about safe access to the tracks by the electrical controllers, signallers should know the implication of failures on their area and its impact on their adjacent control sectors. All of these activities require planning and overall understanding of the railway operations. Successful implementation means understanding the impact of the change on the overall organisation:

"I think the biggest challenges are with people and culture, information management may provide the system that would tick the boxes, but unless we actually get their understanding on board as early as possible then you are doing nothing."

This includes the need to understand the effect on various roles and how to engage the wider organisation with the project to facilitate system acceptability. 
Looking through the findings from the interview study, and in relation to the data processing framework of the discussion, it appeared that human factors can be clustered into three high level groups corresponding to different roles and activities. Task design, workload and human computer interaction relate to the need for successful manipulation of raw data into meaningful information, presented efficiently and without imposing unmanageable workload, monitoring, decision making and problem solving relate to diagnostic roles where operators apply their expertise in understanding and managing a fault. Finally planning and organisational culture should be in place to ensure that the system works as a whole and it is beneficial for the larger railway operation.

\subsection{Data processing in railway II systems}

The data processing framework first drafted through the familiarisation exercise was assessed through the third iteration of the interview transcription analysis. Since participants were selected from the most knowledgeable informants the concerns connected with data processing, shown in Error! Reference source not found. 5, reflect well their perceived importance within Network Rail. The terms are used here to emphasise the changes in the operators' understanding of the situation and handling or hybrid human automation.

"Intelligence is when we are able to use data to prevent equipment failures. So going back to the ISO standard in these six steps the level of intelligence is increasing. The infrastructure has no level of intelligence in it."

The following describes the different features of data processing and the data processing framework to be shown below.

Asset: any feature used to facilitate the running of the railway - a wide range of equipment on track, such as rail, point machine, level crossing, signal, as well as the embankment where the rail tracks are located - is an asset. Control room equipment such as signalling systems or electrical control room SCADA systems are also considered to be railway assets.

Sensor: assets are remotely located and spread over a very large area with sensors used to enable the collection of data. Sensors range from RCM equipment attached to the point machines to event frequency collectors at ticket barriers to count the number of passengers on each train. 
Data: every asset has a number of attributes, such as age, type, location, etc. Assets also have associated dynamic attributes, such as the current voltage in a point machine or the temperature. Data are logged and collected through sensors and then stored.

Database: the data collected are stored in large databases that can be relational or distributed.

Information: the data in the database have to be interpreted to become meaningful. Attributes such as temperature of a point heater would be analysed on the basis of known standards and values, discrepancies and trends made available to operators. Using simple excel spreadsheets or much more sophisticated information displays.

Information development: being presented with a piece of information would not lead to action. The agent (human operator or computer) should analyse and assess the information made available and develop an understanding of the situation.

Knowledge: information is developed into knowledge through use of advanced diagnostic, predictive or reasoning technologies or human expertise to extend understanding of the situation.

Knowledge integration: the railway is a multi-agent and distributed system, and in order to assess a situation optimally it is necessary to integrate knowledge from various work settings. For example, a signaller should be aware of the situation on track regarding how protection is set up and the work that is being carried out, as well as train movements planned from an adjacent signalling control centre.

Intelligence: the integrated knowledge contributes to action selection, intelligence relating to any supporting decision aid, planning tool or knowledge base. At present only people are capable of making such decisions but the intelligence will eventually be built into an asset.

The interviewees were least concerned with issues associated with databases and sensors, mainly because of their confidence in the available technological advances. Intelligence and knowledge integration received the highest expressions of concern, reflecting the immaturity of these.

[Figure 5]

4.4 Integration of the thematic content analysis into a data processing framework: from data to intelligence? 
NVIVO $\mathrm{TM}$ facilitates modelling the relationships among themes to identify relevant factors, making it possible to link the human factors relevant to different functions and roles within II. Similarly, it is possible to identify various stages of data processing (described in the previous section) with different functions as well as human factors. Inspection of the outputs from the three different iterations of coding (II, human factors and data processing framework) led to development of the data processing framework presented in Figure 6.

[Figure 6]

The data processing framework shows the transition from raw data captured from an asset through to a database that keeps all of the recorded data and the processes required to interpret these (e.g. algorithms, thresholds), leading to a "smart" course of action. Depending on the roles and responsibilities of the II users, four levels of understanding have been specified:

1. Data: facts not yet interpreted which possibly represent only the evidence of a problem or even just the existence of an asset.

2. Information: relationships between, and integration of, the facts, maybe in the form of cause and effect relationships.

3. Knowledge: interpretation and reasoning applied to the information.

4. Intelligence: consideration of the asset, its condition and any problems within the whole work socio-technical system, in a form to support asset management decisions and more extensive problem solving.

Data and information layers correspond to stages 1, 2 and 3 of ISO 13374 (Figure 2) and enable remote condition measurement of the infrastructure through capturing, sensing, recording and processing of the raw data. The knowledge layer corresponds to the fourth stage of ISO 13374 and enables remote condition monitoring via development of the information. Finally, the intelligence layer corresponds to stages 5 and 6 of ISO 13374 and enables remote condition management through integration of the knowledge within various external effectors.

\section{Discussion}

Automation in the railway has been somewhat piecemeal to date, comprising restricted automation in route setting for signallers, automated (video and lasers) on-train inspection of rail track, automated scanning and sensing at level crossings, etc. Implementation of automation onto the infrastructure to support maintenance and engineering activities has been slower, but the potential of railway intelligent 
infrastructure is to be an integrated rather than piecemeal implementation. To achieve this however will require an in-depth understanding of the roles and functions of those who will use the systems, what information will be needed by them, how the millions of bits of information sensed will be reduced to usable knowledge and then intelligence, how the sensors will be interfaced with future robotic systems for automated systems repair, and how the new systems will be integrated into the work of the users.

Three key roles were specified for users of the railway II system: track workers, control room operators, and strategic or business analysts. In order that sensible decisions can be made about the types and levels of data processing, and of related operations systems, thorough background knowledge is required about the existing functions and roles of the potential major user groups. As part of this project, cognitive work analyses were completed for electrical control operators, especially for alarm handling (Dadashi et al, 2012), but there has been less analysis work carried out to date for the other groups (although see Ferreira et al, 2012, and Wilson et al, 2009).

Consideration of the decision making processes under II, and best human factors advice on systems design and implementation, necessitates investigation of the cognitive processes and impacts at various levels of the data processing framework, according to the roles and needs of different staff. The data processing framework will be useful as a support to system design decision making for each of the main functions which will use II and in particular to answer questions such as: what the data will be used for, how massive quantities of raw data could be reduced and filtered for different needs of different stakeholders, and what decision support routines are required? Moreover, the decision making processes of track workers, control room operators and strategic analysts are unlikely to require the same type of information as each other, and so this must be accounted for in wider subsequent work.

The data processing framework shows the transition of data during a problem solving activity that is going to feature in the future II. By looking at the manipulation of data the different roles involved with the tasks can be clarified and the data relevant to these roles can be identified.

Working at the three levels within the framework - data and information, knowledge and intelligence - can guide development teams (including ergonomists) in the development of user and human factors requirements, appropriate implementation of automation, and design for job design, team working, communications and decision making support. The tasks associated with the first level, data and information can include rule-based collection of data and storing the measured data in a distributed database. Detailed 
analysis of the tasks and ensuring the reliability of the data are the key factors that designers should be aware of. Issues associated with the workload of those to whom II data are supplied, their trust in the information provided and optimum forms of onscreen information presentation are key factors. Not surprisingly, the other two levels, knowledge and intelligence, are more difficult to automate as the key functions that lead to these forms of understanding are decision making, problem solving and planning. It might be possible to introduce semi-automated decision support systems at local levels (e.g. weather monitoring systems in maintenance control centres). However, for a centralised system such as II, a key benefit lies in the integration of information and knowledge collected from a number of control centres across the country (or at least the performance and contingency plans in the adjacent control rooms to assist the controller to plan optimal course of corrective action). Therefore, detailed understanding of the features and supports that operators use to solve their problems and the information that they use strategically is highly valuable for developers.

Anyone who has worked in the general field of cognitive systems engineering, and specifically within human-centred or adaptive automation, supervisory control, alarms handling and process control operator decision making will be very familiar with the key human factors of II identified in this work. We are not claiming that factors have been identified in figures 6 which were not expected, nor that any expected ones were not identified. However, the aim of the work was to support company planners, engineers and systems analysts to develop improved II which meets industry and company goals, and so it is important that: a) the identification of the factors came directly from the lead company decision makers; and b) that they are captured within a framework familiar to the systems analysts and engineers.

Furthermore, despite the fact that the Kappa statistics of the inter-rater reliability is within the accepted confidence range, it is not a particularly high score. This relatively low score has been expressed a recurring issue in verifying qualitative data (Marques et al., 2005). Within the present study the low confidence score can be due to three main reasons.

Firstly, the Human Factors researchers involved with this coding had different years of experiences, which could suggest that their perception of the importance of various Human Factors issues differed. This has been recognised as a systematic bias (Wagner et al., 2010) where differences in terms of informants (in this case Human Factors coders) could lead to deviations and fluctuations of responses.

URL: http://mc.manuscriptcentral.com/terg E-mail: ergonomics@tandf.co.uk 
Secondly, the first coder conducted the interviews with the railway experts; consequently the coding of the data contained domain specific knowledge and presumptions that was obtained through the interviews.

The third and perhaps the most influential cause that led to some of the differences that was observed amongst the two groups of coding was due to the fact that, some of the human factors concepts highlighted within the study are not isolated from each other (e.g. decision making and automation) and might be coded differently by different Human Factors researchers. Further research is recommended to explore these issues in more detail.

\section{CONCLUSIONS}

This paper reports one of a series of studies that conducted to facilitate an in-depth understanding of railway II. The qualitative data collection enabled a contextual understanding of the topic to be developed. Issues associated with roles, functionalities, benefits and challenges were highlighted and explored with the interviewees. Furthermore, the researchers' understanding of relevant human factors, guided by informant's comments led to mapping various key human factors against requirements for the success of such systems. Finally the framework reported in this study captured the multi-agent nature of II systems, the content of the framework showing the sequence of data processing required for an intelligent decision from the time it gets recorded by a sensor to where the strategic analyst can use it to advise on future policies.

An II system can be thought of as, in effect, a knowledge sharing centre in which information is collected in great quantities, processed and presented to operators to support their decision making. It is not currently intended to replace existing systems and, therefore, users' current responsibilities and priorities will likely remain substantially the same. Railway II is a system that aims to support operators in their daily activity, not necessarily replacing the technologies that they currently use for daily operational activities. Therefore, the quality of information provided to the operators and its effectiveness will determine if the operators choose to use the system or not, or at least to what degree and for what tasks. A critical question remains as to what level of knowledge and information is required for operators to meet their responsibilities in the best way possible and what range of information level is advisory (i.e., not too much or too little). We are all familiar with operators using work-arounds when supplied with a system which they believe makes their job harder, through too much redundant information or insufficient or untimely information that is needed. 
The output of this study will assist rail systems engineers and developers to present an appropriate level of detail for each of the three stages identified for II. More pertinently perhaps, we are using the framework to emphasize to the organization and system developers that there are different and distinct design and information needs of the different jobs and functions (maintenance engineers, quality and compliance specialists, data analysts and management) who will use the system and the intelligence it is intended to support.

One of the earliest mantras behind the moves to an II was the desire to move from a find and fix philosophy and approach to one of predict and prevent. This raises interesting questions for the systems planners and designers, of where exactly and by what/who the prediction and prevention will be carried through. With find and fix there was no doubt - finding faults was through staff out on track or by operators interpreting alarms and alerts in control centres, with the fix being largely carried out by teams of specialist or non-specialist staff on site. The big question then is of how the framework we have developed will support role allocation and work bank decisions within the II system. In order that the wider socio-technical systems concerns and requirements can be better understood, the schematic shown in figure 7 has been produced. This is based upon interpretation of the wider literature as well as Network Rail documentation as well as on the interviewees' comments, makes it clear that the human factors contributions must be wider than the information display interfaces alone, important as these are. It is through knowledge of the goals and functions of the different roles involved in making future intelligent infrastructure a success, and the capabilities of those filling the roles (including elements of automated and robotic systems) that socio-technical design decisions will be made. Many of the key functions which are removed from the immediate interaction with II will involve planning and decision making - for instance decisions on sensitivity settings and sampling rates for sensors, decisions of data cleaning and reduction/representation, and on the use of on-track staff, control room operators or robotics repair to implement the preventive mechanisms. What will underlay many of the organisational and technical systems design decisions will be how the system is viewed by managers and engineers. If a narrow technological focus is taken, with the system being the hardware and software then the organisation of maintenance and renewal work will be very different than if a socio-technical systems view dominates, whereby decisions over what work is to be done and when are made by a joint human-machine system.

[Figure 7]

\section{References}


Adeli, H., \& Jiang, X. (2009). II, Neural Networks, Wavelets, and chaos theory for intelligent transportation systems and smart structures. Taylor \& Francis Group, LLC.

Adriaens, P., Goovaerts, P., Skerlos, S., Edwards, E., \& Egli, T. (2003). II for sustainable potable water: a roundtable for emerging transnational research and technology development needs. Biotechnology Advances, 22(1-2), 119134.

Aktan, A. E., Helmicki, A. J., \& Hunt, V. J. (1998). Issues in health monitoring in II. IOP electronic journal.

Bainbridge, L. (1983) "Ironies of automation," Automatica, vol. 19, pp. 775-779.

Balfe, N. (2010). Appropriate automation of rail signalling systems: a human factors study. Unpublished PhD thesis, school of mechanical, materials, and manufacturing engineering. The University of Nottingham, Nottingham. 2012

Carayon, P. (2006). Human factors of complex sociotechnical systems. Applied ergonomics, 37(4), 525-535.

Crainic, T. G., Gendreau, M., \& Potvin, J.-Y. (2009). Intelligent freight-transportation systems: Assessment and the contribution of operations research. Transportation Research Part C: Emerging Technologies, 17(6), 541-557. Elsevier Ltd.

Campbell, J. L. (1988). Collapse of an industry:Nnuclear Power and the contradictions of US policy. NY: Cornell University Pr.

Cullen, Rt Hon Lord. (2000). The ladbroke grove rail inquiry. Part 1 Report, Norwich: HSE Books, HMSO.

Dadashi, N. (2012). Human Factors of Future Rail II. Unpublished PhD thesis, school of mechanical, materials, and manufacturing engineering. The University of Nottingham, Nottingham.

Dadashi, N., Wilson, J. R., Golightly, D., Sharples, S., \& Clarke, T. (2013). Practical use of work analysis to support rail electrical control rooms: A case of alarm handling. Proceedings of the Institution of Mechanical Engineers, Part F: Journal of Rail and Rapid Transit, 227(2), 148-160

Dft, Rail Trends, Great Britain 2010/11= Rail Statistics Factsheet No.1. Retrieved from http://assets.dft.gov.uk/statistics/series/rail/110805 Rail_Factsheet.pdf (Available on Oct 2014).

Ferreira, P., Clarke, T., Wilson, J., Sharples, S., \& Ryan, B. (2008). Resilience in rail engineering work. In Hollnagel, E., Pieri, F., Rigaud, E., Proceedings of the third Resilience Engineering Symposium. Ecole des mines de Paris, Paris: France.

Gilson, R. D., Mouloua, M., \& Graft, A. S. (2001). Behavioural influences of proximal alarms. Human Factors, 43(4), 595-610.

Golightly, D., Wilson, J.R., Lowe, E. \& Sharples, S. (2010). The role of Situation Awareness for understanding signalling and control in rail operations. Theoretical issues in Ergonomics Science, 11-12. 
Hameed, Z., Hong, Y., Cho, Y., Ahn, S., Song, C., 2009, Condition monitoring and fault detection of wind turbines and related algorithms: A review. Renewable and Sustainable Energy Reviews, vol. 13, 1-39.

Hoc, J. M. (2001). Towards a cognitive approach to human-machine cooperation in dynamic situations. International Journal of Human-Computer Studies, 54, 509540 .

Hollnagel, E., \& Woods, D.D. (2005). Joint Cognitive Systems: Foundations of Cognitive Systems Engineering: An Introduction to Cognitive Systems Engineering, CRC Press Inc.

Hull, G.J., Roberts, C., Hillmansen, S. (2010). Simulation of energy efficiency improvements on commuter Railways. In: Proceeding of IET Conference on Railway Traction Systems, RTS 2010; Birmingham

Jardine, A.K.S.; D. Lin; and D. Banjevic (2006). "A review on machinery diagnostics and prognostics implementing condition-based maintenance." Mechanical Systems and Signal Processing (v20, n7), 1483-1510.

Johansson, B. and Hollnagel, E. (2007): Pre-requisites for Large Scale Coordination. Cognition, Technology \& Work, 9, 1, 5-13.

Kaber, D. B., \& Endsley, M. R. (2004). The effects of level of automation and adaptive automation on human performance, situation awareness and workload in a dynamic control task. Theoretical Issues in Ergonomics Science, 5(2), 113-153.

Kans, M., \& Ingwald, A. (2008). Common database for cost-effective improvement of maintenance performance. International Journal of Production Economics, 113(2), 734-747.

Lagnebäck, R. (2007). Evaluation of wayside condition monitoring technologies for condition-based maintenance of railway vehicles. Environmental Engineering.

Landis, J. R., \& Koch, G. G. (1977). The measurement of observer agreement for categorical data. biometrics, 159-174.

Lyons, J., \& Urry, G. (2006). Foresight: the place of social science in examining the future of transport. London: Evidence-Based Policies and Indicator Systems.

Marques, J. F., \& McCall, C. (2005). The application of interrater reliability as a solidification instrument in a phenomenological study. The Qualitative Report, 10(3), 439-462.

Marquez, F.P., Schmid, F. (2007). A digital filter-based approach to the remote condition monitoring of railway turnouts. Reliability Engineering \& System Safety, 92 (6), 830-840.

McHutchon, M. A., Staszewski, W. J., \& Schmid, F. (2005). Signal Processing for Remote Condition Monitoring of Railway Points. Strain, 41(2), 71-85.

McNulty, R. (2011) Realising the potential of GB rail. Report of the Rail Value for Money Study.

URL: http://mc.manuscriptcentral.com/terg E-mail: ergonomics@tandf.co.uk 
Miles and Huberman, A.M, M. (1994). Qualitative Data Analysis, An Expanded Sourcebook (2nd ed.). SAGE publications.

Neale, H., \& Nichols, Sarah. (2001). Theme-Based Content Analysis : A Method for User Centred Design and Implementation of Virtual Environments Theme-Based Content Analysis : A Method for User Centred Design and Implementation of Virtual Environments. International Journal of Human -Computer Studies, 44, 042.

Network Rail, Railway Industry Association, Metronet, Tube Lines. (2007). II Good Practice Guide.

Network Rail. (2009). Network Rail II Strategy Network Rail.

Noy, Y.A. 1997). Human factors in modern traffic systems, Ergonomics, 40, 10161024.

Omodei, M. M., McLennan, J., Elliott, G. C., Wearing, A. J., \& Clancy, J. M. (2005). "More is Better": A Bias Toward Overuse of Resources in Naturalistic Decision Making Settings. In H. Montgomery, R. Lipshtiz, \& B. Brehmer (Eds.), How Professionals Make Decisions? (29-41).

Patel, H., Pettitt, M. and Wilson, J.R., 2012, Factors of collaborative working: A framework for a collaboration model. Applied Ergonomics, 43, 1-26.

Pickup, L., Wilson, J.R. and Lowe' E, 2010, The operational demand evaluation checklist (ODEC) of workload for railway signalling. Applied Ergonomics, $\underline{41}$ 393-402.

Wilson, J., \& Clarke, Theresa. (2003). Mental Workload of the Railway Signaller. Contemporary Ergonomics.

Roth, E. M. (2008). Uncovering the requirements of cognitive work. Human Factors: The Journal of the Human Factors and Ergonomics Society, 50(3), 475-480.

Seagull, F. J., Wickens, Christopher D, \& Loeb, R. G. (2001). When is less more? Attention and Workload in auditory, visual, and redundant patient-monitoring conditions.

Seagull, F. J., \& Sanderson, P. M. (2001). Anesthesia alarms in context: An observational study. Human Factors, 43, 66-78

Sheridan, Thomas B. (1992). Telerobotics, automation, and human supervisory control (p. 393). MIT Press.

Speier, C., 2006. The influence of information presentation formats on complex task decision-making performance. International Journal of Human-Computer Studies, 64,1115-1131.

Stanton, N.A. (2006). Alarm Initiated Activities. In W. Karwowski (Ed.), International encyclopaedia of ergonomics and human factors (2nd ed., 10081011). Taylor \& Francis Group, LLC. 
Stanton, N. A., \& Baber, C. (2008). Modelling of human alarm handling response times: a case study of the Ladbroke Grove rail accident in the UK.Ergonomics, 51(4), 423-440.

Thunholm, P. (2005). Planning Under Time Pressure: An Attempt toward a Prescriptive Model of Military Tactical Decision Making. In H. Montgomery, R. Lipshitz, \& B. Brehmer (Eds.), How Professionals Make Decision? 43-56.

Timms, C. (2009). Hazards equal trips or alarms or both. Process Safety and Environmental Protection, 87(1), 3-13.

Wagner, S. M., Rau, C., \& Lindemann, E. (2010). Multiple informant methodology: a critical review and recommendations. Sociological Methods \& Research, 38(4), 582618.

Wilkinson, J., \& Lucas, D. (2002). Better alarm handling-a practical application of human factors. Measurement \& Control.

Wilson, J.R, Norris, B.J and Clarke, T. \& Mills, A. (EDS), eds., 2005. Rail Human Factors: Supporting the Integrated Railway. Ashgate: London

Wilson, J.R, Norris, B.J and Clarke, T. \& Mills, A. (EDS), eds., 2007. People and Rail Systems: Human Factors at the Heart of the Railway: Ashgate: London

Wilson, J.R. \& Norris, B.J., 2006. Human factors in support of a successful railway: a review. Cognition Technology and Work, 8, 4-14

Wilson, J.R., Mills, A., Clarke, T., Rajan, J. and Dadashi, N., Rail Human Factors around the World: Impacts on and of people for Successful Rail Operations. Taylor and Francis: London, 2012.

Wilson, J.R., Ryan, B, Schock, A and Pitsopoulos, J, 2009, Understanding safety and production risks in rail engineering planning and protection, Ergonomics, $\underline{52}$, 774-790.

Woods, David D. (1995). The alarm problem and directed attention in dynamic fault management. Ergonomics, 38(11), 2371-2393.

Woods, D.D. and Branlat, M. (2010). Hollnagel's test: being 'in control' of highly interdependent multi-layered networked systems. Cognition, Techology \& Work, $12,95-101$. 
25

26

27
28

28
29

30

31

33

34

35

36

37

39

40

41

42

44

45

46

47

48

49

51

52

53

54

55

57

58

59

60

URL: http://mc.manuscriptcentral.com/terg E-mail: ergonomics@tandf.co.uk 
List of Figures

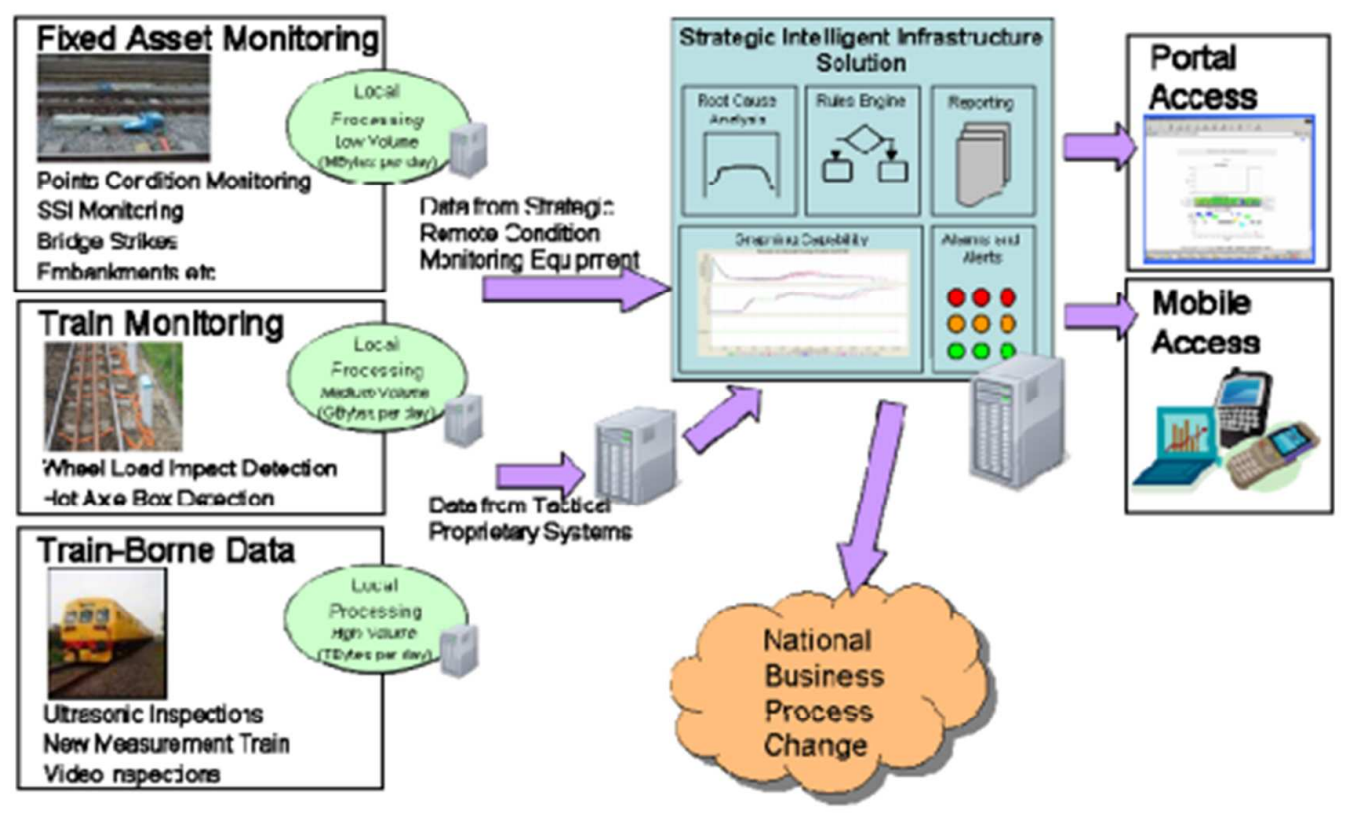

Figure 1: High level model of the RCM internal network rail communication

URL: http://mc.manuscriptcentral.com/terg E-mail: ergonomics@tandf.co.uk 
Figure2: ISO 13374 strategic framework taken from Network Rail, 2009 


\begin{tabular}{|c|c|c|c|c|c|}
\hline Benefit & Current RCM situation & $\begin{array}{l}\text { Future plans } \\
\text { futula }\end{array}$ & Functions & Cognitive functions & Challenge \\
\hline $\begin{array}{l}\text { We have drawn a conceptual benefit } \\
\text { model with two axes benefit and time. } \\
\text { Time has an important factor in the } \\
\text { context of intelligent infrastructure } \\
\text { project }\end{array}$ & $\begin{array}{l}\text { At the moment the how we look after } \\
\text { infrastructure is completely passive, } \\
\text { something breaks on the track, you as a } \\
\text { technician get alerted and fix it }\end{array}$ & $\begin{array}{l}\text { so we need to specify exactly what data } \\
\text { we need }\end{array}$ & $\begin{array}{l}\text { This is to identify what state the asset is } \\
\text { and it gives binary measures, is it working } \\
\text { nomally or is it working abnomally }\end{array}$ & $\begin{array}{l}\text { For example if the data shown suggest } \\
\text { that you have four days to fix this } \\
\text { problem but maybe the operator says I am } \\
\text { in the area now and this is a critical asset, } \\
\text { a golden asset and it can fail and it is } \\
\text { better to fix it as soon as possible. Here } \\
\text { scheduling and prionitising is very } \\
\text { important to consider }\end{array}$ & $\begin{array}{l}\text { The problem of this ratl } \\
\text { acquisition is generatin } \\
\text { amount of data }\end{array}$ \\
\hline , we can't afford delays & $\begin{array}{l}\text { This is being done to some extent at the } \\
\text { moment. For example we do measure } \\
\text { point heating and this data is being } \\
\text { collected every second, and the time } \\
\text { interval setup on it is chosen due to }\end{array}$ & $\begin{array}{l}\text { part of the project is to collect the right } \\
\text { amount of data at the right interval and } \\
\text { also on the right asset }\end{array}$ & $\begin{array}{l}\text { This is a diagnostic position where we } \\
\text { can diagnose from the data we have and } \\
\text { say what is wrong with it. Somewhere in } \\
\text { here between these two steps you need } \\
\text { to inform people somehow }\end{array}$ & & $\begin{array}{l}\text { For example on a point: } \\
\text { measure various things } \\
\text { to switch, force, temper } \\
\text { hydraulic pressure, etc, } \\
\text { need all of these inform }\end{array}$ \\
\hline $\begin{array}{l}\text { So the idea is to get the right information } \\
\text { to the right group of people and stop } \\
\text { bothering others. }\end{array}$ & $\begin{array}{l}\text { currently this is the stage where network } \\
\text { rail is. We have remote condition } \\
\text { measurement systems places on various } \\
\text { assets and we can determine whether the } \\
\text { asset is operating in its nomal condition } \\
\text { or an abnormal condition. }\end{array}$ & $\begin{array}{l}\text { A project in Network Rail entitled } \\
\text { "Network Criticality" is responsible for } \\
\text { this assignment and they have developed } \\
\text { a map of critical assets which is assists } \\
\text { intelligent infrastructure project team with } \\
\text { identification of critical assets }\end{array}$ & $\begin{array}{l}\text { Two types of actions need to be } \\
\text { considered: interim corrective action and } \\
\text { permanent corrective action. Interim } \\
\text { corrective action refers to when the } \\
\text { operator has to fix the problem quickly, } \\
\text { for example if an error occurs and it is } \\
\text { going to cause delay the maintenance } \\
\text { team might decide to fix the error straight } \\
\text { away, two options are available }\end{array}$ & & $\begin{array}{l}\text { The risk in handling the } \\
\text { intelligently is that we a } \\
\text { up with huge amount o: } \\
\text { alerts being raised on d } \\
\text { categories with differen } \\
\text { and the problem is how } \\
\text { present that data to ope } \\
\text { that we get the right rea }\end{array}$ \\
\hline $\begin{array}{l}\text { The main objective is to keep the cost } \\
\text { and waste of data services down by just } \\
\text { collecting the key pieces of data }\end{array}$ & $\begin{array}{l}\text { Today in most cases we just have an } \\
\text { alarm and alert approach. Local operators } \\
\text { set the limits for the assets in their area } \\
\text { and when an abnormality occurs it will }\end{array}$ & $\begin{array}{l}\text { one of the requirements of the intelligent } \\
\text { infrastructure projects is to align these } \\
\text { various legacy systems }\end{array}$ & $\begin{array}{l}\text { Permanent corrective action: this might } \\
\text { involve contacting suppliers with an } \\
\text { enhanced set of information to be } \\
\text { provided to a more strategic group }\end{array}$ & & Partially this is due to $t$ \\
\hline
\end{tabular}

FIGURE 3: EXAMPLE EXTRACT FROM THE SPREADSHEET USED FOR EARLY STAGES OF DATA COLLATION 


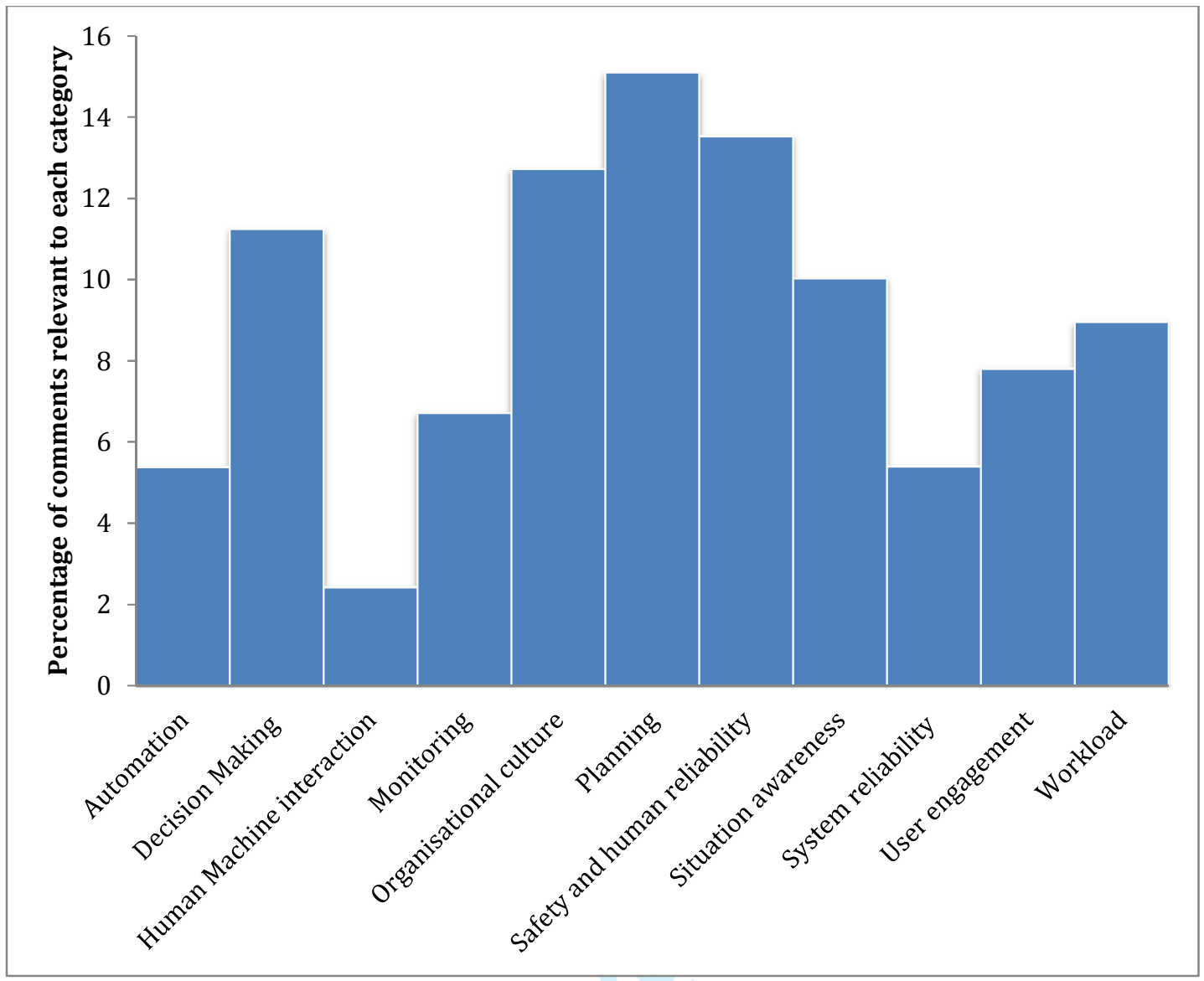

FIGURE 4: INTERVIEW ANALYSIS: HUMAN FACTORS ISSUES IN RAILWAY II

URL: http://mc.manuscriptcentral.com/terg E-mail: ergonomics@tandf.co.uk 


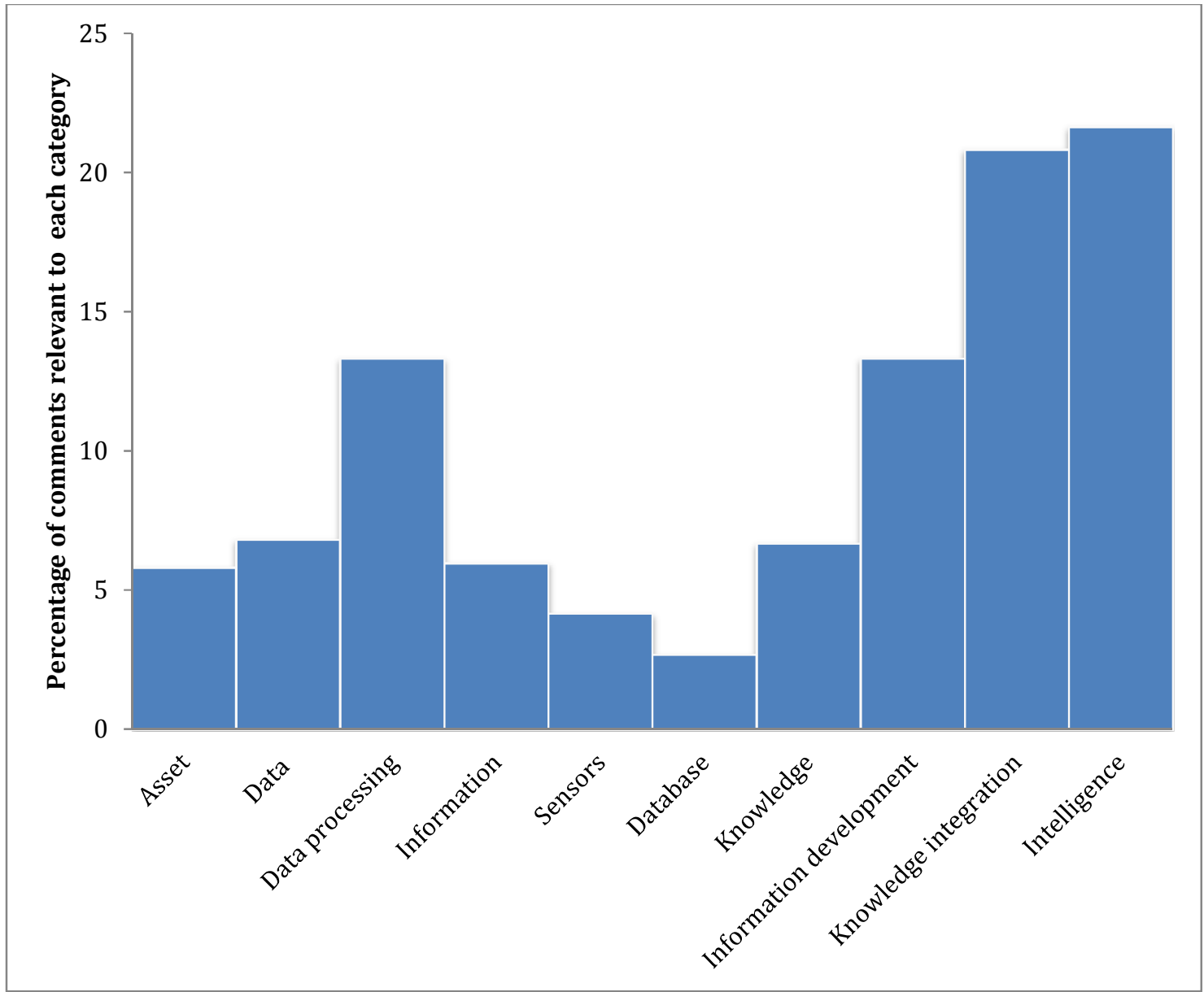

FIGURE 5: INTERVIEW ANALYSIS: DATA PROCESSING FRAMEWORK IN RAILWAY II

URL: http://mc.manuscriptcentral.com/terg E-mail: ergonomics@tandf.co.uk 


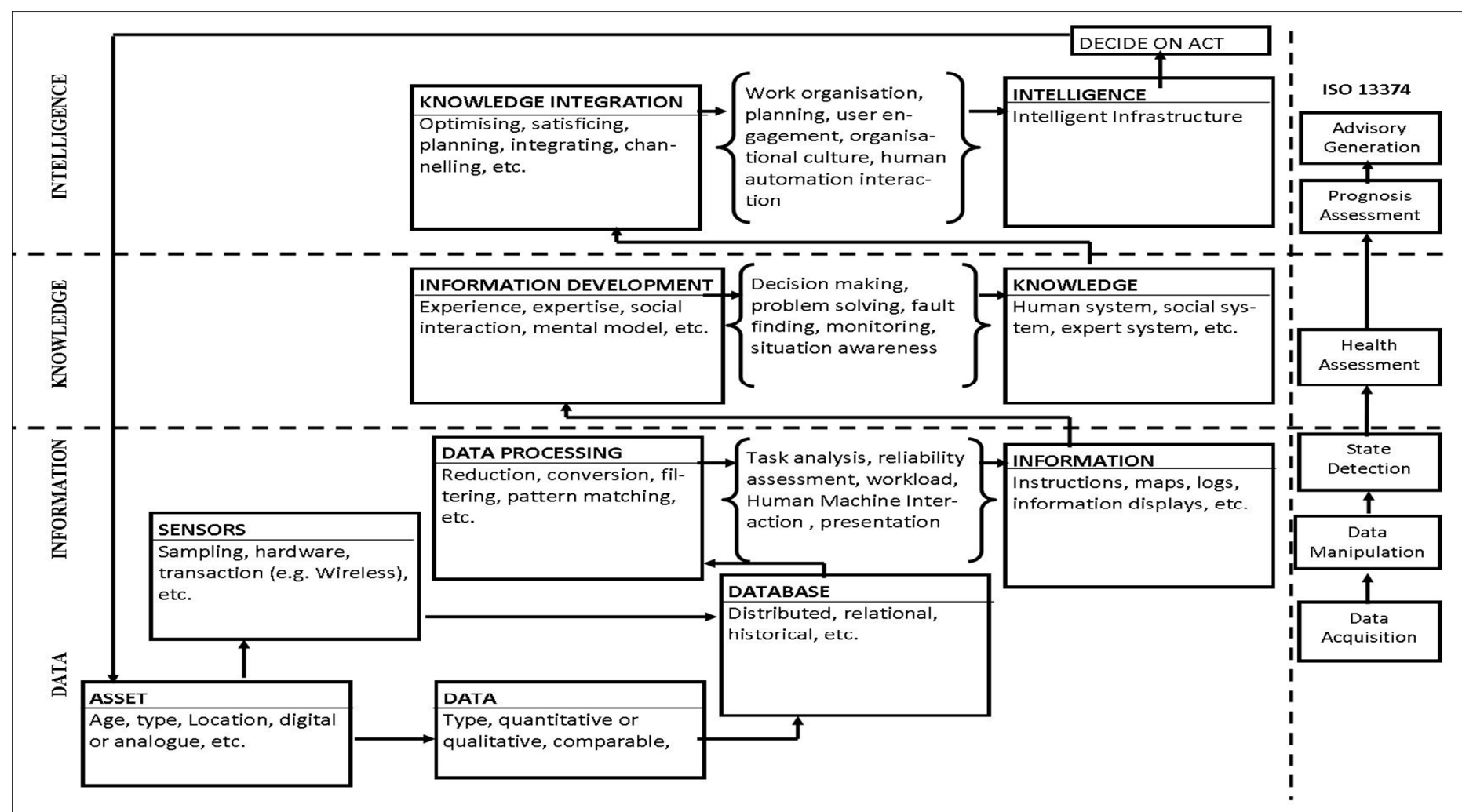

FIGURE 6: DATA PROCESSING FRAMEWORK OF RAILWAY II 
FIGURE 7: WIDER

SYSTEMS

REPRESENTATION

OF INTELLIGENT

INFRASTRUCTURE

Design settings:

sampling,

frequency, sensitivity etc
Physical environment - weather, vibration, impacts etc

Physical setting (fixed asset, train etc) - access

etc

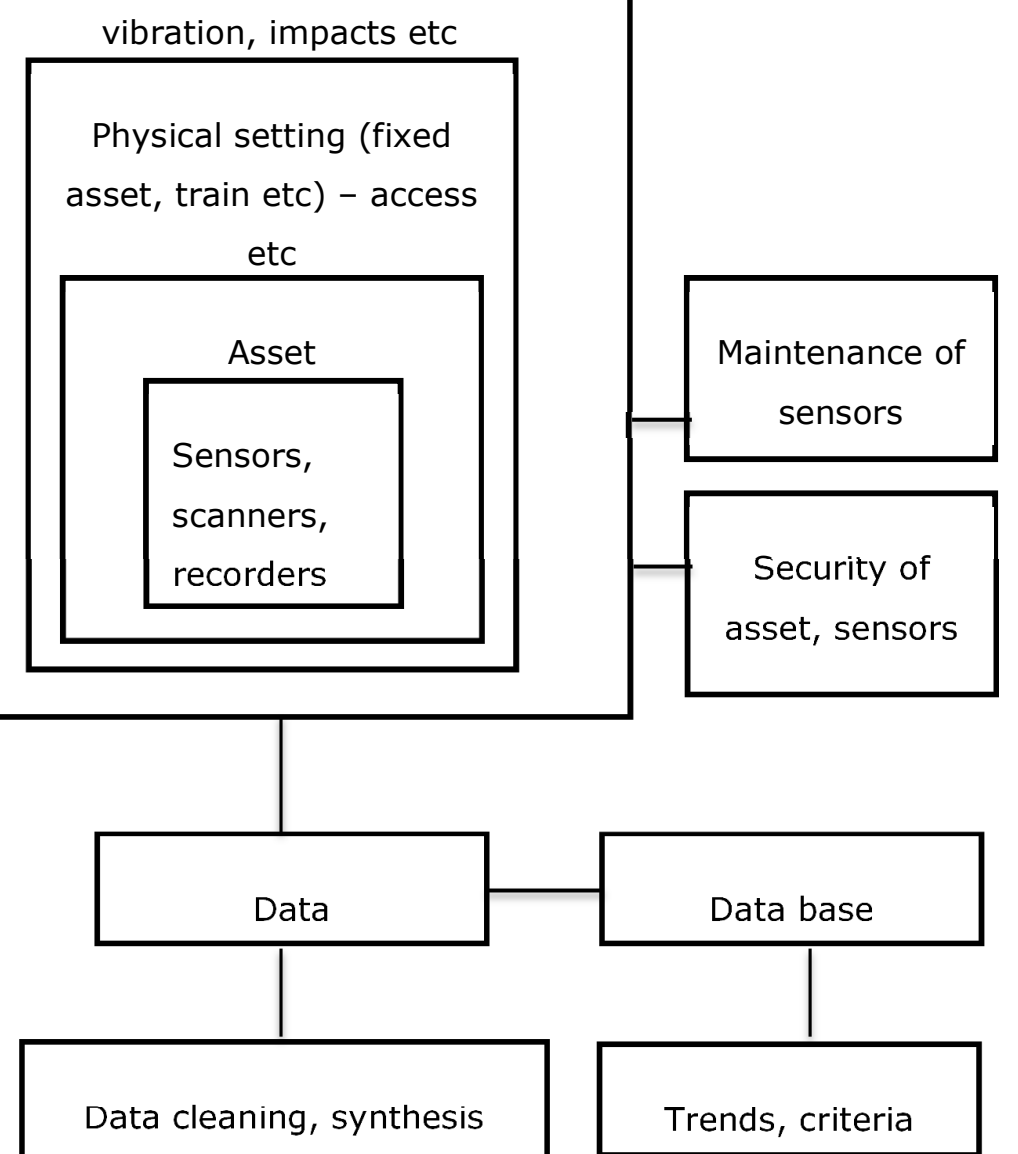

and reduction

Decision support system

Socio-technical and organisational context

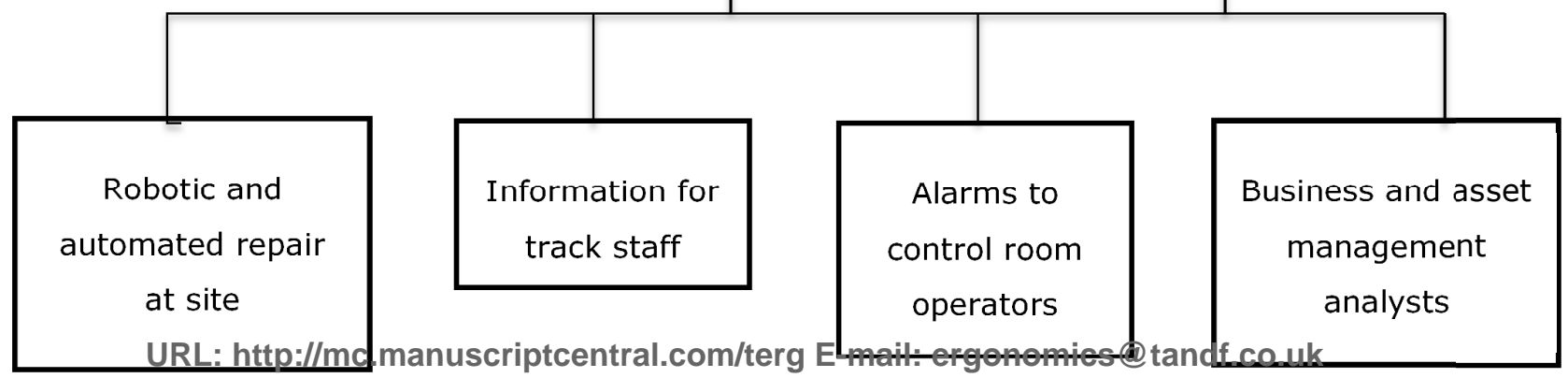

